Artigo Original

\title{
Inserção da Educação Física na área de Linguagens, Códigos e suas Tecnologias
}

\author{
Marlene de Fátima dos Santos ${ }^{1}$ \\ Daniel Marcon ${ }^{2}$ \\ Daiane Toigo Trentin ${ }^{3}$ \\ ${ }^{1}$ Escola Municipal de Ensino Fundamental "Felipe Jacob Klein", Vale Real, RS, Brasil \\ ${ }^{2}$ Curso de Educação Física, Universidade de Caxias do Sul, RS, Brasil \\ ${ }^{3}$ Instituto Federal de Educação, Ciência e Tecnologia do Rio Grande do Sul, \\ Campus Ibirubá, RS, Brasil
}

\begin{abstract}
Resumo: Os Parâmetros Curriculares Nacionais para o Ensino Médio introduziram a Educação Física na área de Linguagens, Códigos e suas Tecnologias, juntamente com as disciplinas Língua Portuguesa, Artes, Informática, Literatura e Língua Estrangeira Moderna. Diante disso, este trabalho se propôs a investigar como professores das referidas disciplinas interpretam a inserção da Educação Física nessa área. Participaram deste estudo de caso qualitativo 16 professores de três escolas públicas estaduais, com mais de 1.500 alunos. Os resultados, obtidos por meio de questionário, evidenciam a dificuldade dos professores de trabalhar interdisciplinarmente, de identificar as relações possíveis entre as disciplinas e, inclusive, de reconhecer a Educação Física como integrante da área de Linguagens, Códigos e suas Tecnologias. Essas constatações configuram, portanto, aspectos relevantes a serem considerados no desafio de implementação das proposições legais nas escolas da Educação Básica.
\end{abstract}

Palavras-chave: Ensino médio. Linguagem. Interdisciplinaridade.

\section{Inserting Physical Education in the area of Languages, codes and their technologies}

\begin{abstract}
The High School National Curriculum Parameters introduced Physical Education in the area of Languages, Codes and their Technologies, along with other subjects like Portuguese language, Arts, Information Technology, Literature and Foreign Modern Language. Thus, this study aimed to investigate how teachers understand Physical Education in this area. For achieving this, a qualitative case study was done, in which 16 teachers from three public state schools with over 1.500 students. The results, obtained through a questionnaire, demonstrate the teachers' difficulty in developing interdisciplinary projects, in identifying the possible relations among disciplines, and even in recognizing Physical Education as part of the area of Languages, Codes, and their Technologies. These are, therefore, important issues to be considered in the challenge of implementing the legal propositions in the schools of Primary Education.
\end{abstract}

Keywords: High school. Language. Interdisciplinarity.

\section{Introdução}

A proposição de três áreas do conhecimento Ciências Naturais, Matemática e suas Tecnologias; Linguagens, Códigos e suas Tecnologias (ALCT); Ciências Humanas e suas Tecnologias - pelos Parâmetros Curriculares Nacionais do Ensino Médio (PCNEM) (BRASIL, 2000), tem constituído importante orientação para a análise e a reestruturação dos currículos da Educação Básica, bem como para a superação dos recorrentes isolamento e fragmentação das disciplinas curriculares. Outros documentos oficiais compartilham esse objetivo (BRASIL, 2000; 1998; 2002), dentre os quais se destacam a Lei de Diretrizes e Bases da Educação Nacional (LDB) (BRASIL, 1996) e as Orientações
Curriculares para o Ensino Médio (OCEM). (BRASIL, 2006).

Em sua essência, esses documentos conferem à disciplina Educação Física a responsabilidade de levar os estudantes a experimentar, conhecer e apreciar diferentes práticas corporais sistematizadas, compreendendo-as como produções culturais dinâmicas e diversificadas (GONZÁLES; FRAGA, 2009). Em tese, são essas as características que justificam a inserção da Educação Física na ALCT, juntamente com as disciplinas de Língua Portuguesa, Literatura, Informática, Artes e Língua Estrangeira Moderna. 
A ALCT privilegia a aquisição e 0 desenvolvimento de competências gerais relacionadas à representação, à comunicação, à investigação, à compreensão e à contextualização sociocultural, de modo que os alunos conheçam e saibam usar diferentes linguagens em distintas situações ou contextos. Os PCNEM e as OCEM preconizam, inclusive, que as linguagens não sejam desenvolvidas apenas como formas de expressão e de comunicação, mas como constituidoras de significados, conhecimentos e valores. (BRASIL, 2000; 2006).

Esses são alguns dos pressupostos que balizam a implantação, pela Rede Estadual de Ensino do Rio Grande do Sul, dos referenciais curriculares Lições do Rio Grande. (RIO GRANDE DO SUL, 2009). Esse documento evidencia a necessidade de que as situações de ensino e aprendizagem ocorram de maneira contextualizada, de modo que os conteúdos da matéria de ensino das diferentes disciplinas sejam tanto relacionados entre si quanto com as questões reais da vida dos alunos e aos fatos que o cercam e lhes fazem sentido.

Diante dessas proposições da legislação, a presença da Educação Física na ALCT se explicaria pelo uso da linguagem corporal - que estimula a comunicação em distintas culturas e contextos - como elemento central no processo de interação dos alunos com a cultura corporal de movimento. Como forma de participação e interação social, a linguagem corporal propicia ao indivíduo o reconhecimento do outro e de si mesmo. De acordo com Mattos e Neira (2000), as linguagens podem ser definidas como instrumentos de conhecimento e construção de mundo e, por isso, podem ser consideradas um elemento mediador da aprendizagem e do desenvolvimento humano.

Para Ladeira e Darido (2003) é na escola que se deve evidenciar a importância de todas as linguagens enquanto constituintes do conhecimento e das identidades dos alunos. É nas aulas de Educação Física que os alunos darão início à produção de textos e à leitura dos diferentes textos corporais; onde eles desenvolverão as suas interpretações a respeito da dança, do jogo, da luta, da ginástica e do esporte e passarão a compreendê-los como elementos da cultura corporal de movimento.

Embora represente a principal interface da Educação Física com as demais disciplinas da
ALCT e tenha participação significativa na cultura corporal de movimento, a linguagem corporal não figura como elemento central de estudo dessa disciplina. A Educação Física não se limita, pois, ao estudo das formas de se expressar e de se comunicar corporalmente, mas é concebida como área de conhecimento e de intervenção profissional que,

tem como objeto de estudo e de aplicação o
movimento humano, com foco nas diferentes
formas e modalidades do exercício físico, da
ginástica, do jogo, do esporte, da luta/arte
marcial, da dança, nas perspectivas da
prevenção de problemas de agravo da saúde,
promoção, proteção e reabilitação da saúde, da
formação cultural, da educação e da
reeducação motora, do rendimento físico-
esportivo, do lazer, da gestão de
empreendimentos relacionados as atividades
físicas, recreativas e esportivas, além de outros
campos que oportunizem ou venham a
oportunizar a prática de atividades físicas,
recreativas e esportivas. (BRASIL, 2004, p. 16).

Nessa esteira, Matthiesen et al. (2010) advertem que a linguagem corporal - apesar de ser um tema compartilhado com as demais matérias de ensino da ALCT - não pode ser entendida como elemento fundamental de estudo da Educação Física. Por outro lado, quando a Educação Física está relacionada ao ensino da linguagem, seu foco necessita ser geral (apud Labarrière, 1999). Sobre isso, Mattos e Neira (2000) propõem que o ensino da linguagem corporal no Ensino Médio privilegie a compreensão e a utilização das formas de expressão, como gestos e movimentos, seus significados, suas técnicas e táticas, em que os alunos sejam capazes de ler e compreender uma dança, um jogo ou um esporte, percebendo e interpretando o que se passa e interferindo neles de forma eficiente e estratégica.

É na consideração dessas questões supostamente divergentes no que tange ao objeto de estudo e à própria identidade da Educação Física, do contexto histórico atual, de plena implantação e avaliação da viabilidade dessas propostas, e da sua relevância para a legitimação dessa disciplina na ALCT e na Educação Básica, que este estudo se propôs a investigar como professores da ALCT: justificam a presença e a importância da Educação Física na estrutura curricular do Ensino Médio; concebem a interdisciplinaridade de suas disciplinas com a Educação Física; e interpretam a contribuição da Educação Física para o desenvolvimento das competências objetivadas pela ALCT. 


\section{Métodos}

Para alcançar os objetivos estabelecidos nesta investigação, optou-se pela realização de um estudo de caso qualitativo, descritivo e de corte transversal. (DENZIN, 2006; YIN, 2010).

O grupo de participantes foi formado por 16 professores que ministravam, no Ensino Médio, as disciplinas integrantes da ALCT em três escolas da Rede Estadual de Ensino, cada uma delas com mais de 1.500 alunos, de uma cidade do interior do Rio Grande do Sul.

Para a coleta de informações utilizou-se um questionário, elaborado, com base na literatura consultada, especificamente para esta investigação. As nove questões abertas que compunham 0 questionário instigavam os professores à reflexão sobre a importância e as contribuições da disciplina de Educação Física para a ALCT e para ao Ensino Médio, bem como sobre as possibilidades de estabelecimento de relações interdisciplinares entre a sua disciplina ministrada e as demais disciplinas que compõem a ALCT, com atenção especial à Educação Física.

Foram entregues 40 questionários - com nove questões abertas - para as três escolas, dos quais 16 retornaram respondidos pelos professores, sendo: quatro de Educação Física, quatro de Língua Inglesa, dois de Artes, cinco de Língua Portuguesa e Literatura, e um de Língua Espanhola. À época da realização da investigação, as escolas participantes não dispunham de professores de Informática.

As transcrições textuais das respostas dissertativas dos questionários tiveram suas unidades de significado identificadas, analisadas quanto ao seu conteúdo e classificadas em três categorias de análise. As categorias de análise foram construídas a partir, justamente, dos três objetivos da investigação, bem como com o apoio da literatura, e assim enunciadas: Importância da Educação Física na estrutura curricular do Ensino Médio; Interdisciplinaridade entre as disciplinas de Línguas e Artes e de Educação Física; e Contribuições da Educação Física para a ALCT.

Para analisar as informações, optou-se, inicialmente, pelo estabelecimento de um paralelo entre as informações disponibilizadas pelos dois grupos analisados - professores de Educação Física (PEF) e professores de Línguas e Artes
(PLA) - em cada uma das três categorias de análise, sendo essas categorias analisadas separadamente. Posteriormente, foi traçado um novo paralelo entre as resultados das três categorias de análise, buscando-se as possíveis relações entre elas.

O projeto de pesquisa foi aprovado pelo Comitê de Ética em Pesquisa com Seres Humanos (registro CEP/FUCS no 237/2009). A Coordenadora Regional de Educação e os Diretores de cada escola autorizaram a realização da investigação por meio da assinatura do Termo de Consentimento Livre e Esclarecido. Todos os professores participantes também assinaram esse Termo, concordando explicitamente em participar voluntariamente e em disponibilizar suas informações para publicação.

\section{Resultados e discussão}

Importância da Educação Física na estrutura curricular do Ensino Médio

Para Correia (2009), a Educação Física necessita assumir seu papel no âmbito do Ensino Médio a partir de conhecimentos sistematizados e aprofundados sobre os aspectos inerentes à cultura corporal de movimento. $\mathrm{O}$ autor considera fundamental o estabelecimento de uma dimensão crítica no reconhecimento dos limites e das precariedades das recomendações curriculares provenientes dos PCNEM.

Para os professores da ALCT, participantes desta investigação, a inserção da Educação Física no currículo do Ensino Médio é justificada pela capacidade dessa disciplina de contribuir para o desenvolvimento e para a formação integral dos alunos, abrangendo os aspectos cognitivo, afetivo e motor. Tais questões podem ser exemplificadas pela fala de dois participantes: "A Educação Física é importante por tratar o aluno como um todo." (PLA 7). "De extrema importância, pois a Educação Física, em toda sua abrangência, [...] desenvolve o ser como um todo." (PEF 3). Essas declarações sugerem concepções de Educação Física atreladas à construção de conhecimentos que fazem parte da cultura corporal historicamente produzida, vinculados ao esporte, ao jogo, à dança, à ginástica e às lutas.

É fato que as pessoas, ao se movimentarem, expressam sentimentos, emoções e pensamentos, ampliando as possibilidades do uso significativo de gestos e posturas corporais. $O$ 
movimento humano, nesse caso, é mais que um simples deslocamento do corpo no espaço; constitui-se em uma linguagem que permite aos seus participantes agirem sobre o meio físico e atuarem sobre o ambiente humano, mobilizando as pessoas por meio de seu teor expressivo.

Apesar disso, conforme adverte Bracht (2005), esse discurso da "formação integral" foi incorporado à Educação Física sob uma perspectiva pedagógica progressista e crítica, pois sua intenção era, principalmente, fugir da dicotomia corpo/mente. Esse viés da Educação Física ganhou força entre muitos professores da área, o que elevou o discurso da "formação integral" a um status que sugere completude e que, supostamente, dispensaria maiores esclarecimentos sobre seu real significado.

Os professores de Educação Física investigados foram questionados sobre a importância atribuída à disciplina na estrutura curricular do Ensino Médio. A tendência das respostas centrou-se no próprio objeto de estudo da disciplina, ou seja, a cultura corporal de movimento, como exemplifica a fala de um deles: "É a disciplina que desenvolve a cultura corporal, formação de hábitos, autoestima, convivência em grupo, lazer." (PEF 1).

Por cultura corporal de movimento entende-se um conjunto de práticas ligado ao corpo e ao movimento, que foi construído pelo homem ao longo de sua história. Os PCNEM apontam que a Educação Física, como disciplina escolar, necessita tratar da cultura corporal, em sentido amplo, e que sua finalidade é introduzir e integrar o aluno a essa esfera, formando o cidadão que vai produzi-la, reproduzi-la e transformá-la, visando a uma ressignificação das práticas comuns nas aulas dessa disciplina. (BRASIL, 2000).

De modo a compreender como percebem a Educação Física no Ensino Médio, instigou-se os professores pesquisados à reflexão sobre essas questões a partir de suas vivências. Os professores de Línguas e Artes foram unânimes ao afirmar que, nas aulas de Educação Física, os alunos recebem uma bola dos desportos tradicionais (futebol, basquetebol, handebol ou voleibol) e jogam livremente, sem qualquer intervenção pedagógica. Tal concepção pode ser identificada nas falas de alguns participantes: "Ela poderia ser mais bem trabalhada, pois os profissionais só jogam a bola na quadra e os alunos não têm estímulo e nenhum incentivo." (PLA 1). "Já vi muita aula de Educação Física ser somente 'dar a bola para o aluno'. Acho que não pode ser assim, pois há muitas possibilidades de trabalho a ser desenvolvido." (PLA 5).

Entre outros autores, Betti (1999), Bracht (1997) e Soares et al. (1992) questionam a utilização da prática esportiva como conteúdo principal das aulas de Educação Física no Ensino Médio sem um embasamento teórico que priorize, para além das regras, os contextos antropológico, sociológico e filosófico. Nesses casos, a disciplina encontra dificuldades para justificar sua importância como integrante do currículo da Educação Básica.

De acordo com os PCNEM (BRASIL, 2000), um dos objetivos da Educação Física no Ensino Médio é o aprofundamento e a consolidação de conhecimentos construídos no Ensino Fundamental. No entanto, essa continuidade não é observada na prática, já que, no Ensino Médio, as aulas de Educação Física costumam repetir os programas do Ensino Fundamental, resumindo-se às práticas dos fundamentos de alguns esportes $\mathrm{e}$ à execução dos gestos técnicos esportivos (BRASIL, 2000), justamente como verificado na interpretação dos professores de Línguas e Artes participantes da investigação.

Nota-se que tanto na opinião dos professores de Educação Física quanto na dos professores de Línguas e Artes, a Educação Física, como área de conhecimento, exerce importante papel na estrutura curricular do Ensino Médio, ao contribuir para o desenvolvimento "integral" do aluno. Ao mesmo tempo, os professores de Línguas e Artes lamentam que a falta de compromisso com a prática docente, por parte de alguns professores, dificulte 0 alcance desses objetivos e torne a Educação Física, dentro da ALCT e na estrutura curricular do Ensino Médio, uma disciplina isolada.

Embora concordem que a Educação Física não demonstra seu valor e sua importância dentro da ALCT e no currículo escolar do Ensino Médio, o ponto de vista dos professores de Educação Física é de que tal situação se deve mais às concepções equivocadas dos alunos a respeito da disciplina do que à sua própria prática pedagógica, como explica um professor: "De acordo com minhas vivências, só consigo definir [a Educação Física] como os alunos 
inconscientemente conceituam: como um tempo de recreação." (PEF 4).

Acredita-se, portanto, que a importância da Educação Física na ALCT e na estrutura curricular do Ensino Médio necessita ser demonstrada pelos próprios professores da disciplina - por meio do seu fazer pedagógico não ficando sujeita às interpretações que os alunos e os professores de outras disciplinas têm a seu respeito.

\section{Interdisciplinaridade entre as disciplinas de Línguas e Artes e de Educação Física}

As Diretrizes Curriculares Nacionais para o Ensino Médio (BRASIL, 1998), e mais recentemente as próprias OCEM (BRASIL, 2006), incluem a interdisciplinaridade como um dos princípios norteadores da construção do conhecimento. Voltada à formação do indivíduo, a proposta da interdisciplinaridade traz implícita a capacidade de diálogo das diversas ciências entre si, e a interpretação do saber como um só, e não, em partes ou de maneira fragmentada. (FAZENDA, 1994).

A interdisciplinaridade, na visão dos professores de Línguas e Artes e dos professores de Educação Física investigados, representa uma forma de integrar e de articular o conhecimento originado nas diferentes disciplinas. Porém, ambos os grupos afirmam que essa é uma tarefa de difícil execução e que requer mais estudos e tempo para se concretizar: "Importante, pois são necessárias a integração e a articulação do conhecimento em um processo permanente e contextualizado." (PLA 3). "A interdisciplinaridade é sempre bem vinda, pois assim o aluno entende que somos uma unidade de conhecimento e não um ponto isolado." (PLA 6). "É interessante! O problema é conseguir reunir, organizar e pôr em prática o mesmo trabalho com diversas disciplinas." (PEF 1).

Para Thiesen (2008), o novo processo de aprender e ensinar, e a rede de relações que engendra o mundo atual indicam o novo caminho da educação diante das demandas sociais, sobretudo das mediadas pela tecnologia. Nessa direção, a educação e as formas de ensinar e de aprender não são mais as mesmas, e um processo de ensino baseado na transmissão linear e parcelada da informação, provavelmente, não será suficiente. Nesse complexo trabalho, esclarece 0 autor, o enfoque interdisciplinar aproxima o sujeito de sua realidade mais ampla, auxilia os aprendizes na compreensão das complexas redes conceituais e possibilita maior significado e sentido aos conteúdos da aprendizagem, permitindo uma formação mais consistente e responsável.

As preocupações, nesse caso, vão desde a valorização do tempo e do espaço da sala de aula até a relação de mediação entre $o$ aluno e a construção do conhecimento. A perspectiva interdisciplinar, integrando as várias disciplinas curriculares, demonstra aos alunos que não existem fronteiras entre as disciplinas, mas que todas se perpassam e se complementam reciprocamente. Para Câmara (1999), a interdisciplinaridade necessita ser pensada como o espaço que compreende o intervalo entre ciências; por um lado, se considera o território de cada uma delas e, concomitantemente, se identificam possíveis áreas de entrecruzamento, de possíveis conexões. Essa busca se realiza por meio de um processo dialógico que permite novas interpretações, mudança de visão, avaliação crítica de pressupostos, um aprender com o outro e, enfim, uma nova reorganização do pensar e do fazer.

Conforme explica Pereira (2009), a interdisciplinaridade deve ser uma ação conjunta entre os professores e suas disciplinas, visando à compreensão do todo que se constitui o conhecimento. Thiesen (2008) ressalta, ainda, que a interdisciplinaridade é um movimento importante de articulação entre o ensinar e o aprender. Compreendida como formulação teórica e assumida como atitude, a interdisciplinaridade tem a potencialidade de auxiliar os educadores e as escolas na ressignificação do trabalho pedagógico em termos de currículo, de métodos, de conteúdos, de avaliação e nas formas de organização dos ambientes para a aprendizagem. (PEREIRA, 2009; THIESEN, 2008).

Os professores participantes da pesquisa, quando questionados sobre como se sentiam para atuar numa perspectiva interdisciplinar, afirmaram que a troca de conhecimento entre as disciplinas é muito interessante, pois vem a somar no aprendizado dos alunos. Mesmo assim, eles declararam não se sentir à vontade para levar adiante suas crenças, à medida que esbarram na falta de formação específica para isso, na falta de tempo para um planejamento conjunto e na necessidade de colaboração de todos os 
professores, visto que muitos são resistentes às mudanças: "Me sinto um pouco assustada, pois o desafio é grande e depende da vontade de todo o grupo." (PLA 2). "A minha faculdade não desenvolveu nenhuma forma ou perspectiva interdisciplinar." (PLA 7). "Não [me sinto] muito preparada, mas, se todos os colegas tivessem o mesmo objetivo e interesse, o projeto interdisciplinar ficaria mais fácil. O problema é que alguns não concordam com nada, não querem mudanças." (PEF 1).

Para Pereira (2007), a falta de um entendimento claro sobre como a interdisciplinaridade pode ser colocada em prática, aliada a uma formação inicial marcadamente disciplinar, faz com que os educadores, de modo geral, tenham dificuldades na construção de um ensino que associe conteúdos de diferentes disciplinas, pois isso exige também um trabalho pedagógico de cooperação integrada entre eles. De acordo com o autor, a cooperação integrada do grupo de professores é um ponto-chave para a viabilização da interdisciplinaridade escolar.

A interdisciplinaridade é tratada pelo PCNEM como um eixo integrador, que pode ser representado pelo próprio objeto de conhecimento, por um projeto de investigação ou por um plano de intervenção. Nesse sentido, tais referenciais orientam para que a interdisciplinaridade parta das necessidades e das demandas das escolas, dos professores e dos alunos. (BRASIL, 2002).

No entanto, e conforme destacado anteriormente, quando tentam investir em um trabalho interdisciplinar, os professores esbarram em carências próprias de sua formação, as quais podem ser percebidas, fundamentalmente, na dificuldade de identificar os pontos de permeabilidade entre as várias disciplinas. Isso demonstra, ainda que veladamente, que uma maneira diferente de conceber o processo de construção do conhecimento escolar está sendo introduzida na escola. Devido às exigências impostas pela interdisciplinaridade, os docentes das escolas estão percebendo a necessidade de estudar os objetos de conhecimento de outras disciplinas e de aprender uns com os outros. Refletindo sobre essa necessidade, Fazenda (1994) salienta que a característica da atitude interdisciplinar é a ousadia da busca, da pesquisa, e a transformação da insegurança num exercício do pensar, num construir juntos.

A necessidade de romper com a tendência fragmentadora e desarticulada do processo de construção do conhecimento, segundo Brandl (2003), justifica-se pelo reconhecimento da importância da interação e da transformação recíprocas entre as diferentes áreas do saber. Essa compreensão crítica colabora para a superação da divisão do pensamento e do conhecimento que vem conceituando o ensino como sendo o processo reprodutor de um saber parcelado.

Contribuições da Educação Física para a área de Linguagens, Códigos e suas Tecnologias

A inserção da Educação Física na ALCT, a partir da proposição dos PCNEM (BRASIL, 2000) e das OCEM (BRASIL, 2006), ao mesmo tempo que procurou integrá-la ao processo educacional e concebê-la como uma das linguagens, também buscou contribuir para a superação do estigma de ser uma disciplina isolada e que pouco contribui para a formação dos alunos. (RAMOS, 2006). Apesar da importância que há em se discutir tal inclusão, as informações disponibilizadas pelos participantes deste estudo evidenciam pouco esclarecimento $e$, até mesmo, relativa incompreensão a respeito da área.

Quando questionados sobre as possíveis relações da sua disciplina com as demais disciplinas da área, os professores de Educação Física responderam de maneira genérica e pouco específica, o que sugere falta de clareza e de discernimento quanto às possibilidades. Do mesmo modo, quando instigados à reflexão sobre as estratégias e os conhecimentos que poderiam ser abordados de forma interdisciplinar, os professores de Educação Física estabeleceram relações com disciplinas de outras áreas, como Biologia, Física, História, Geografia e Matemática, e não, com as demais disciplinas da ALCT, como Língua Portuguesa, Línguas Estrangeiras e Artes, por exemplo.

Esse posicionamento é respaldado por Matthiesen et al. (2008), quando aventam que a Educação Física também poderia ter sido classificada como integrante da área de Ciências Humanas e suas Tecnologias, uma vez que tem forte ligação com os conhecimentos produzidos historicamente, e que se convencionou denominar cultura corporal ou cultura corporal de movimento. 
Os autores afirmam, ainda, que muitos profissionais da Educação Física teriam ficado bastante satisfeitos caso a disciplina de Educação Física tivesse sido agrupada à área de Ciências Naturais, juntamente com a disciplina de Biologia, na interface possível da área com questões relativas à saúde e à qualidade de vida. (MATTHIESEN et al., 2008). Os resultados dos estudos de Miranda et al. (2009) reforçam a hegemonia do viés biológico atribuído à Educação Física, visto que os professores investigados também vincularam a Educação Física à temas atinentes à disciplina de Biologia.

Por essas reflexões, alguns questionamentos emergem: Não estaria a Educação Física descontextualizada na área de Linguagens? Seriam suficientemente claros aqueles argumentos que embasaram a decisão de inserir a Educação Física na ALCT? De fato, como constatam Matthiesen et al. (2008), poucos estudos sobre a Educação Física escolar têm se dedicado a investigar as relações dessa com as demais disciplinas integrantes da ALCT.

Considerar a Educação Física uma linguagem, além de não ser tarefa simples nem óbvia, também abrange muitos conceitos novos e que são pouco transparentes em suas definições originais, dificultando o estabelecimento de relações mais estreitas com o corpo em movimento. (DUARTE, 2010). Quando refletem sobre a interatividade, o diálogo e a construção de significados na, pela e com a linguagem, Mattos e Neira (2000) apontam que o verdadeiro papel da disciplina de Educação Física mantém relações mais evidentes com a saúde e a qualidade de vida do que com as linguagens.

Ladeira e Darido (2003) apresentam outra faceta para interpretar essa nova significação atribuída à Educação Física, à medida que ultrapassa a ideia de se ensinar exclusivamente o gesto motor e diversifica o universo de práticas, como danças, lutas e diferentes esportes, de modo que os alunos ampliem seus conhecimentos relacionados à cultura corporal de movimento.

O que se observa, portanto, são divergências entre as concepções de professores da ALCT participantes desta e de outras investigações sobre a temática - e as proposições da legislação educacional. Diante disso, torna-se fundamental que o tema seja trazido para debate tanto na formação inicial de professores nessas diferentes áreas do conhecimento quanto entre os próprios professores da Educação Básica que ministram disciplinas integrantes da ALCT, visto que, sob a perspectiva legal, essa tende a ser a nova configuração do ensino da área.

\section{Considerações Finais}

Passada mais de uma década da estruturação e proposição dos PCNEM, esforços aos quais se somaram, mais recentemente, as OCEM, percebe-se que os diferentes níveis de governo, fundamentalmente estaduais e municipais, continuam buscando mecanismos que viabilizem a sua implantação nas escolas, o que explicita a complexidade e o desafio inerente a essa tarefa. Mesmo que as preocupações manifestadas pela legislação sejam genuínas e relevantes, elas não são originais e atuais, visto que estão em pauta há muitos anos. Questões como interdisciplinaridade, trabalho em conjunto de professores de diferentes disciplinas e aproximação e agrupamento dessas disciplinas por áreas de conhecimento recorrentemente voltam à tona como "novas" alternativas para qualificar o ensino e a formação dos alunos.

Como procurou demonstrar o presente estudo, a inserção da disciplina de Educação Física na ALCT é motivo de controvérsias e de muitas discussões, pois os próprios professores de Educação Física, responsáveis pelo alcance daqueles objetivos governamentais, não conseguem concebê-la como uma linguagem e nem estabelecer relações com as demais disciplinas que compõem a área.

Essas considerações fazem acreditar que os PCNEM e as OCEM não contemplam, de modo aprofundado, as contribuições da Educação Física para a ALCT, nem explicitam como as aulas dessa disciplina podem ser abordadas sob tal perspectiva, o que gera sentimentos de insegurança e de descontentamento por parte dos professores, levando-os aos consequentes descrédito e abandono dessas propostas.

Adicionalmente, e endossando o ponto de vista de autores analisados, acredita-se que recaia sobre a própria Educação Física a responsabilidade de demonstrar sua importância e de justificar sua presença na ALCT e no currículo escolar do Ensino Médio; ou seja, cabe à própria Educação Física a tarefa de levar até as outras disciplinas as suas contribuições, e não, esperar que elas venham buscar essa integração. 
As evidências demonstram, ainda, que tanto os professores de Educação Física quanto os demais professores da ALCT percebem e reconhecem a importância da Educação Física na estrutura curricular do Ensino Médio. Os professores investigados foram unânimes, também, ao apontar as contribuições do trabalho interdisciplinar no processo de ensino e aprendizagem, o qual, segundo eles, proporciona aos alunos compreender o conhecimento como um todo, e se configura como uma forma de melhorar sua interação com os colegas e de repensar sua prática docente.

No entanto, as dificuldades manifestadas pelos professores, no sentido de integrar as disciplinas de Línguas e Artes e a disciplina de Educação Física podem ser compreendidas não apenas por meio da análise da sua própria prática pedagógica nas escolas, mas também, e fundamentalmente, por meio da análise dos processos e programas de formação de professores de Educação Física nas universidades.

O tradicional distanciamento existente entre as distintas áreas do conhecimento no Ensino Superior é agravado pela própria crise de identidade que acompanha a Educação Física. Em determinadas Instituições de Ensino Superior a Educação Física insere-se nos centros de educação, para onde necessita levar, também, a sua faceta da área da saúde. Em contrapartida, em outras Instituições de Ensino Superior, a Educação Física integra os centros da saúde, para onde necessita levar as suas especificidades concernentes à docência na Educação Básica.

Diante do exposto, evidencia-se a complexidade que impregna o debate referente à inserção da disciplina de Educação Física na ALCT e a importância do tema para os processos de formação inicial e continuada de professores de Educação Física, bem como para o alcance dos objetivos tanto da ALCT quanto da própria disciplina de Educação Física no currículo escolar do Ensino Médio.

\section{Referências}

BETTI, I. C. R. Esporte na escola: mas é só isso, professor? Motriz. Revista de Educação Física. UNESP, Rio Claro, v. 1, n. 1, p. 25-31, jun. 1999. Disponível em: $<$ http://www.rc.unesp.br/ib/efisica/motriz/01n1/4 Ir ene form.pdf $>$. Acesso em: 3 maio 2010.
BRACHT, V. Educação física e aprendizagem social. 2. ed. Porto Alegre: Magister, 1997.

BRACHT, V. Pesquisa em ação: Educação Física na escola. 2. ed. ljuí: Ed. Unijuí, 2005.

BRANDL, C. E. H. A nova política para o Ensino Médio: um estudo da Educação Física a partir das novas diretrizes e dos novos projetos

pedagógicos. Revista Brasileira de Ciências do Esporte, Campinas, v. 24, n 3, p. 71-86, maio 2003. Disponível em:

$<$ http://www.rbceonline.org.br/revista/index.php/R BCE/article/view/764/438 >. Acesso em: 30 mar. 2010.

BRASIL. Lei de Diretrizes e Bases da Educação Nacional (LDB). Lei 9.394, de 20 de dezembro 2002. Diário Oficial da União, Brasília, 1996. Disponível em: <http://www.planalto.gov.br/ccivil 03/LEIS/L9394. htm>. Acesso em: 30 mar. 2010.

BRASIL. Conselho Nacional de Educação/Secretaria de Educação Média e Tecnológica. Parâmetros Curriculares Nacionais: Ensino Médio. Diário Oficial da União, Brasília, 2000. Disponível em: $<$ http://portal.mec.gov.br/seb/arquivos/pdf/blegais.p df>. Acesso em: 20 mar. 2010.

BRASIL. Conselho Nacional de Educação/Secretaria de Educação Média e Tecnológica. PCN + Ensino Médio: Orientações educacionais complementares aos Parâmetros Curriculares Nacionais. Brasília: Ministério da Educação, 2002. Disponível em: $<$ http://portal.mec.gov.br/seb/arquivos/pdf/linguag ens02.pdf >. Acesso em: 20 mar. 2010.

BRASIL. Conselho Nacional de Educação/Câmara de Educação Básica (CNE/CEB). Resolução 3, de 26 de junho de 1998. Diário Oficial da União, Brasília, DF, Seção I, p. 21, 1998. Disponível em: $<$ http://portal.mec.gov.br/cne/arquivos/pdf/rceb03 98.pdf>. Acesso em: 5 de maio 2010.

BRASIL. Conselho Nacional de Educação/Câmara de Educação Superior (CNE/CES). Parecer 58, de 18 de fevereiro de 2004. Diário Oficial da União, Brasília, DF, 2004. Disponível em:

$<$ http://portal.mec.gov.br/cne/arquivos/pdf/2004/pc es058 04.pdf>. Acesso em: 19 ago. 2009.

BRASIL. Secretaria de Educação Básica. Orientações curriculares para o Ensino Médio: Linguagens, Códigos e suas Tecnologias. Brasília: Ministério da Educação, 2006. 239 p. Disponível em: $<$ http://portal.mec.gov.br/seb/arquivos/pdf/book v 
olume 01 internet.pdf>. Acesso em: 27 out. 2010.

CÂMARA, M. L. B. Interdisciplinaridade e formação de professores na UCG: uma experiência em construção. 1999. 208 f. Dissertação (Mestrado em Educação) Faculdade de Educação, UNB, Brasília, 1999.

CORREIA, W. R. Educação Física no ensino médio: subsídios para um projeto crítico e inovador. Motriz. Revista de Educação Física. UNESP, Rio Claro, v. 15, n. 3, p. 740-740, jul./set. 2009. Disponível em:

$<$ http://www.periodicos.rc.biblioteca.unesp.br/inde x.php/motriz/article/viewFile/2902/2546>. Acesso em: 27 dez. 2010.

DENZIN, N. K.; LINCOLN, Y. S. O planejamento da pesquisa qualitativa: teorias e abordagens. 2. ed. Porto Alegre: Artmed, 2006.

DUARTE, L. R. Educação Física como Linguagem. Motriz. Revista de Educação

Física. UNESP, Rio Claro, v. 16, n. 2, p. 292-299, abr./jun. 2010. Disponível em:

$<$ http://www.periodicos.rc.biblioteca.unesp.br/index. php/motriz/article/view/3492/2934>. Acesso em: 25 maio 2010.

FAZENDA, I. C. A. Interdisciplinaridade: história, teoria e pesquisa. 13. ed. Campinas: Papirus, 1994.

GONZÁLES, F. J; FRAGA, A. B. Caderno do professor: Educação Física. In: RIO GRANDE DO SUL. SECRETARIA DA EDUCAÇÃO.

Referencial Curricular Lições do Rio Grande: Linguagens, Códigos e suas Tecnologias, artes e Educação Física. Porto Alegre: Secretaria da Educação, 2009.

LADEIRA, F. T.; DARIDO, S. C. Educação Física e linguagem: algumas considerações iniciais. Motriz. Revista de Educação Física. UNESP. Rio Claro, v. 9, n. 1, p. 31-39, jan./abr. 2003. Disponível em:

$<$ http://www.rc.unesp.br/ib/efisica/motriz/09n1/Lad eira.pdf>. Acesso em: 30 mar. 2010.

MATTHIESEN, S. Q. et al. Linguagem, corpo e Educação Física. Revista Mackenzie de

Educação Física e Esporte. São Paulo, v. 7, n. 2, p. 129-139, 2008. Disponível em: $<$ http://www3.mackenzie.br/editora/index.php/rem ef/article/viewFile/588/373>. Acesso em: 30 mar. 2010.

MATTOS, M. G.; NEIRA, M. G. Educação Física na adolescência: Construindo o conhecimento na escola. São Paulo: Phorte, 2000. p. 14-17.
MIRANDA, A. C. M.; LARA, L. M.; RINALDI, I. P. B. A Educação Física no ensino médio: saberes necessários sob a ótica docente. Motriz. Revista de Educação Física. UNESP, Rio Claro, v. 15, n. 3, p. 621-630, jul./set. 2009. Disponível em: $<$ http://www.periodicos.rc.biblioteca.unesp.br/inde x.php/motriz/article/view/2948/2499>. Acesso em: 30 mar. 2010.

PEREIRA, I. Educação Física e Interdisciplinaridade no Ensino Fundamental. 2007. Disponível em:

$<$ http://www.webartigos.com/articles/3045/1/Educac ao-Fisica-E-Interdisciplinaridade-No-Ensino-

Fundamental/pagina1.html >. Acesso em: 30 abr. 2010.

PEREIRA, R. R. Os professores de Educação Física e Interdisciplinaridade. In: MOLINA NETO, V. Quem aprende? Pesquisa e formação em Educação Física escolar. ljuí: Ed. da Unijuí, 2009.

RAMOS, J. R. S. A Educação Física nos Parâmetros Curriculares Nacionais do Ensino Médio: possíveis contribuições dos estudos lingüísticos para a linguagem corporal. In: X ENCONTRO FLUMINENSE DE EDUCAÇÃO FÍSICA ESCOLAR 2006, Niterói. Anais... Niterói: UFF, Departamento de Educação Física e Desportos, 2006. Disponível em:

<http://cev.org.br/biblioteca/a-educacao-fisica-nosparametros-curriculares-nacionais-ensino-mediopossiveis-contribuicoes-dos-estudos-linguisticospara-linguagem-corporal>. Acesso em: 1 maio 2010.

RIO GRANDE DO SUL. Secretaria da Educação. Referencial Curricular Lições do Rio Grande do Sul: Linguagens, Códigos e suas Tecnologias (Artes e Educação Física). Governo do Estado do Rio Grande do Sul, Porto Alegre, v. 2, p. 184, 2009. Disponível em:

$<$ http://www.educacao.rs.gov.br/dados/refer curric vol2.pdf >. Acesso em: 25 mar. 2010.

SOARES, C. L. et al. Metodologia do ensino de Educação Física. São Paulo: Cortez, 1992.

THIESEN, J. S. A interdisciplinaridade como um movimento articulador no processo ensinoaprendizagem. Revista Brasileira de Educação, Rio de Janeiro, v. 13, n. 39, p. 545-598, set./dez. 2008. Disponível em:

<http://www.scielo.br/pdf/rbedu/v13n39/10.pdf >. Acesso em: 2 mar. 2010.

YIN, R. K. Estudo de caso: planejamento e métodos. 4. ed. Porto Alegre: Bookman, 2010. 
Endereço:

Daniel Marcon

Curso de Educação Física (UCS)

Rua Francisco Getúlio Vargas, 1130, Petrópolis

Caxias do Sul RS Brasil

95070-570

Telefone/Fax: (UCS): (54) 32182213

e-mail: drdmarcon@gmail.com

Recebido em: 7 de dezembro de 2011.

Aceito em: 4 de abril de 2012.

\section{(c) (i)}

Motriz. Revista de Educação Física. UNESP, Rio Claro,

SP, Brasil - elSSN: 1980-6574 - está licenciada sob

Creative Commons - Atribuição 3.0 